\title{
New understanding of climate change on the Qinghai- Tibetan Plateau and its adapting counter-measures
}

\author{
$\underline{\text { Peijun Shi }}^{\mathrm{a}, \mathrm{b}, \mathrm{c}, \mathrm{d}}$, Tao Ye $\mathrm{e}^{\mathrm{b}, \mathrm{c}, \mathrm{d}}$ and Yanqiang Chen \\ aAcademy of Plateau Science and Sustainability, People's Government of Qinghai Province \& Beijing \\ Normal University, ${ }^{b}$ State Key Laboratory of Earth Surface Processes and Resource Ecology, Beijing \\ Normal University, ' Academy of Disaster Reduction and Emergency Management, Ministry of Emergency \\ Management and Ministry of Education, ${ }^{d}$ Faculty of Geographical Science, Beijing Normal University \\ Email:spj@bnu.edu.cn
}

\begin{abstract}
Climate changes in its mean, variability, and extremes, exhibiting obviously spatial-temporal difference. As the "Third Pole" (TP) of the world, the Qinghai-Tibetan Plateau (QTP, abbreviated also as TP for simplicity) plays crucial roles of source and sink of global warming. Global climate change has mainly influenced the climate on the TP and also its glaciers, snow lines, permafrost and ecological systems. Most part of the TP has been getting warmer and wetter, with increased frequency of night-time rainfall, and increased carbon sink. Small part of the TP has become warmer and drier, with decreased carbon sink. The key countermeasure to adapt to climate change on the TP is to develop ecological industry cluster, including carbon-trade, high plateau national park (tourist and sight-seeing industry), health care industry, green animal husbandry, etc.
\end{abstract}

Keywords: The Qinghai-Tibetan Plateau, climate change, ecological system response, ecological industry cluster 
Shi et al., New understanding of climate change on the Qinghai-Tibetan Plateau and its adapting countermeasures

\section{INTRODUCTION}

The TP is a unique geological-geographical-ecological unit on the Earth, and a natural laboratory to study the evolution of earth and life, the interaction of spheres, and coupled human-environment relationship (Zhanget al. 2002). The TP is the youngest and highest plateau on the Earth, reaching the Pamirs and Hindukush in the west, Hengduan Mountains in the east, Kunlun Mountains and Qilian Mountains in the north, and Himalaya in the south, with average elevation of over $4000 \mathrm{~m}$. Recently, new features has been reported on the interaction of the TP and global climate change. As the "third pole" of the world, the TP plays crucial roles of source and sink of global warming. Global climate change has mainly influenced the climate on the TP, and also its glaciers, snow lines, permafrost and ecological systems (Yao 2018). The key countermeasure to adapt to climate change on the TP is to develop ecological industry cluster.

\section{SOME NEW INSIGHTS TO CLIMATE CHANGE ON THE TP}

The preliminary results of the second TP comprehensive scientific survey show that, the Himalaya which raised rapidly since 2.4 million years ago and been higher than the TP, has blocked the northward pathway of south Asia monsoon. Its stream diversion has got the TP gradually drier, and turned South China from desert environment to monsoon humid climate, and a place of fish and rice.

Global climate change (mainly warmer and more humid) has accelerated the liquiding of the TP, the Asian water tower, accompanied with more frequent large-scale disasters. There was obvious warming trend in the TP during 1961-2016, with a rate of $0.33^{\circ} \mathrm{C} /$ decade. The speed of warming in western Tibet, Lhasa, Naqu, and Bange was $0.4^{\circ} \mathrm{C} / \mathrm{decade}$, significantly higher than global and China average. An obvious wetter trend was also detected in the TP, with annual precipitation increasing at a rate of $4.2 \mathrm{~mm} /$ decade. Northeast, central and southeast part of the TP were with even higher rate, $10 \mathrm{~mm} /$ decade. In most parts of the TP, annual average, winter and summer mean precipitation was rising, with increased frequency and intensity of extreme precipitation. Rapid decrease of glacier was also founded in the TP in the past 50 years(Figure 1; Figure 2.). Its aggregate glacier area reduced from $53000 \mathrm{~km}^{2}$ to $45000 \mathrm{~km}^{2}$. By contrast, the number of lakes in the TP increased from 1081 to 1236, and the total area increased from $40000 \mathrm{~km}^{2}$ to $47400 \mathrm{~km}^{2}$. Lakes in the monsoon region has experienced in lower water level due to reduced precipitation, while lakes in the inward flowing zone has benefited from melting glaciers. Expansion of lakes increased the storage of liquid water in the Asian water tower. Runoff in major rivers in the TP has increased significantly, and the major contributor is water from melting glacier. The increase of liquid water brings larger uncertainty of water supply, and also the risk of icy lake burst, flood, debris flow, and engineering harm.

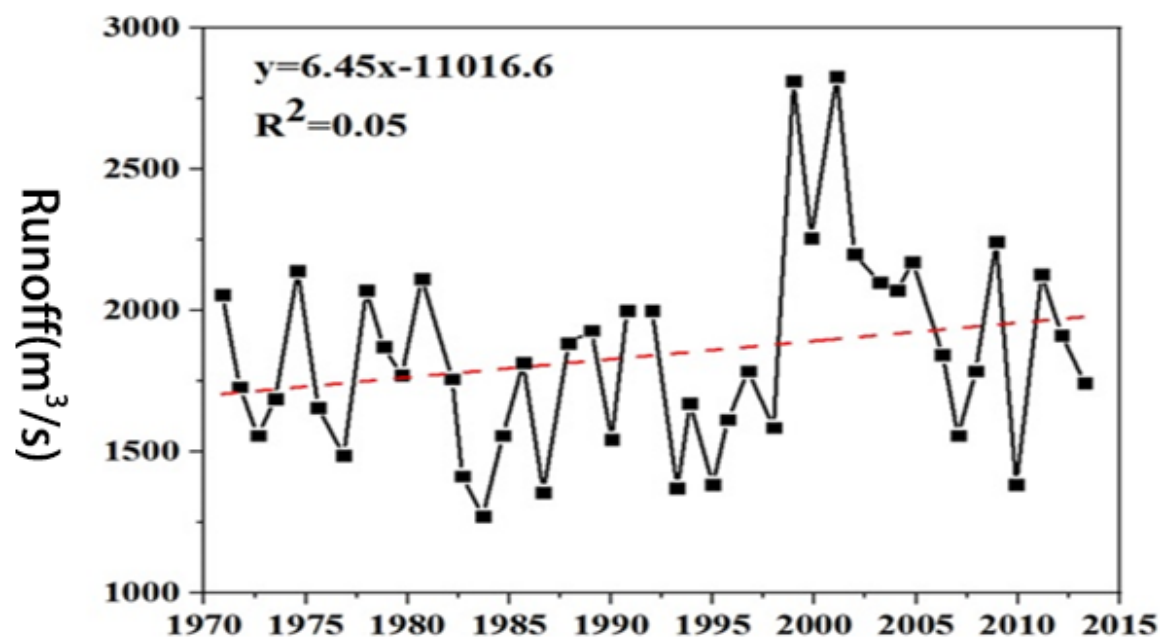

Figure 1. Annual runoff changes in the Brahmaputra (Yao, 2018) 
Shi et al., New understanding of climate change on the Qinghai-Tibetan Plateau and its adapting countermeasures

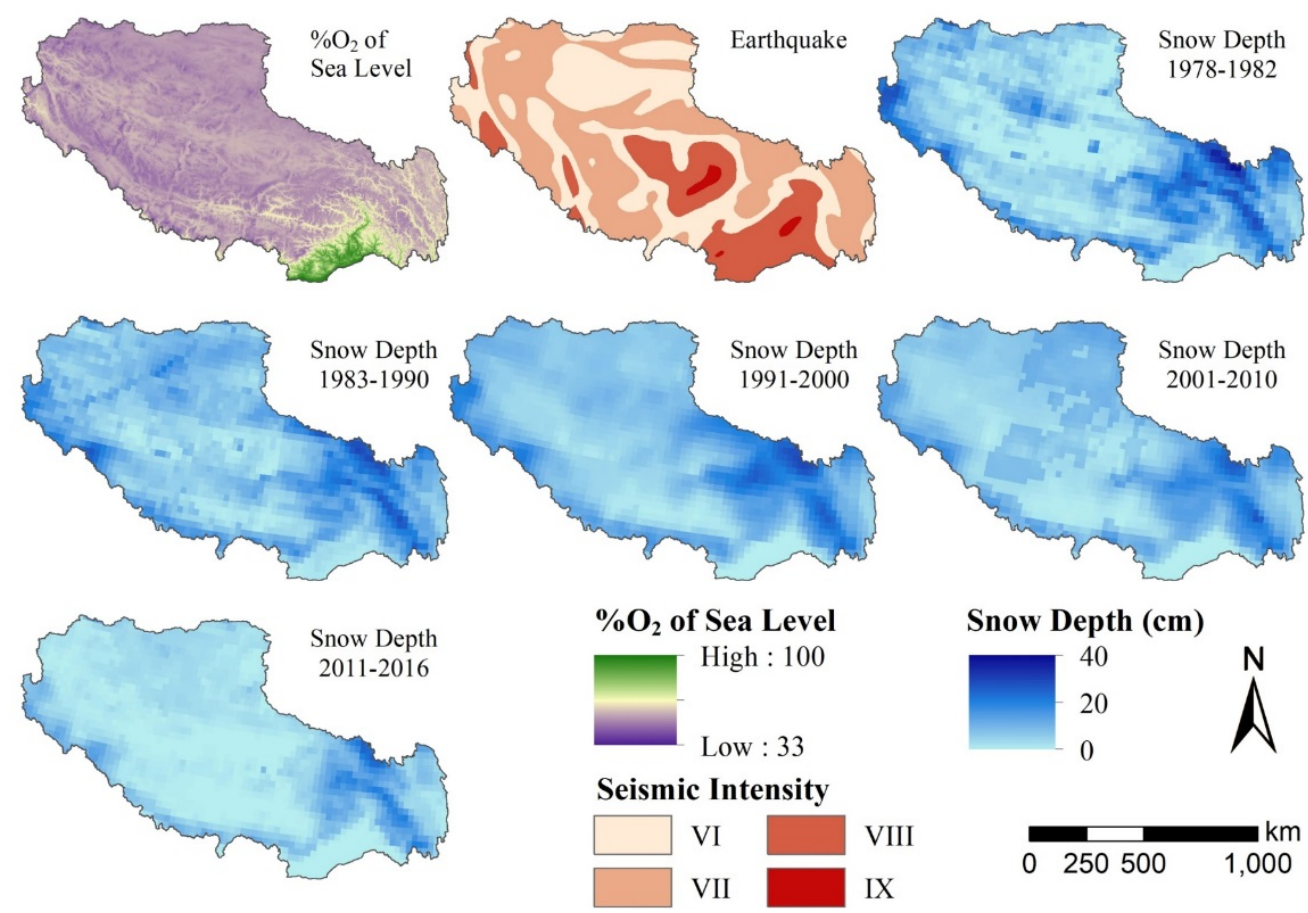

Figure 2. Spatiotemporal Changes of Hazard Intensity-Adjusted Population Exposure to Multiple Hazards in Tibet during 1982-2015 (Zhang et al. 2017)

Vegetation in the TP has been improving in the past 35 years, although the rate of improving slowed down since 2000 ( Yao 2018). From 1980s, warming in the TP has prolonged the active growing season of vegetation, with advanced vegetation green-up date, and delayed withered phase. Growing season average vegetation index has increased $3.2 \%$ in the past 35 years. Due to the increase in vegetation, the carbon sink function of the TP enhanced significantly. From 1980, ecosystem in the TP absorbed $41 \mathrm{TgC}$ per year. From 2000, the figure was $51 \mathrm{TgC} / \mathrm{a}$, taking up 15-23\% of total carbon absorbed by the entire terrestrial ecosystem of China. Nevertheless, climate warming has increased the depth of active permafrost layer, with a rate of $7.5 \mathrm{~cm} / \mathrm{a}$, which has increased the likelihood of releasing carbon in the permafrost, and may turn permafrost from a carbon sink to a source.

Forest covers $11.3 \%$ of the area of the TP, entailing an important component of plateau ecological security. The TP has a complete altitudinal belt of vegetation from rain forest to alpine meadow, and the highest elevated alpine tree line in the north hemisphere, which are sensitive indicators of climate change impact on alpine ecosystems. In the past 100 years, the tree line has increased $29 \mathrm{~m}$ on average, and the maximum value is 80 meters. The rise of tree line has increased biomass of forest, but squeezed the biomes of alpine bush-meadow, and broke the distribution of bio-diversity, leading to vanishing risk of plateau-special species.

The warmer and wetter trend of the TP has also severely influenced agro-ecosystem. Highland barley in the TP has benefited from improved cultivar, irrigation, and the use of chemical fertilizer and pesticide. The impact of warming was not significant during 1985-2000. However, highland barley yield decreased $0.2 \mathrm{t} / \mathrm{ha}$ for every $1{ }^{\circ} \mathrm{C}$ increase in growth-period average temperature. The response could be even stronger under warmer scenarios. It is predicted that, under the $2^{\circ} \mathrm{C}$ and $4^{\circ} \mathrm{C}$ warming scenarios, highland barley yield would drop 0.32 $\mathrm{t} /$ ha in response to $1^{\circ} \mathrm{C}$ increase in growth-period average temperature. It imposes a serious challenge to local agricultural production to adapt to climate change. 
Shi et al., New understanding of climate change on the Qinghai-Tibetan Plateau and its adapting countermeasures

\section{SOME THOUGHTS AND SUGGESTIONS ON THE COUNTERMEASURES TO CLIMATE CHANGE ON THE TP}

\subsection{Some thoughts on the countermeasures to climate change on the TP}

The primary results of the second TP scientific survey illustrated that the environment of the third pole is changing severely. The interaction of westerlies and Indian monsoon is the major driver of environmental change on the third pole. Warmonger above global average has served as the amplifier of environmental change in the TP. From previous climate change aspect, the warming speed on the third pole is twice of global average. If the global average follows the $2{ }^{\circ} \mathrm{C}$ warming limits as written in Paris agreement, the warming in the TP would actually be $4{ }^{\circ} \mathrm{C}$. Huge uncertainty remains in the degree that such a drastic climate change would influence local eco-environment and human activity. Glaciers recession, lakes expansion, icy lakes outbursting, frequent flooding induced by climate warming will threat the economic development of countries along the 'Belt and Road'. Meanwhile, glacier melting water is an important water source of the third pole.

Special surface processes such as desertification has aggravated the eco-environment deterioration in the TP. Four out of six economic corridors along the 'Belt and Road' are threaten by desertification. The compound effect of anthropological PM 2.5 emission with sand-dust storm has become the most severe threat to environment and human health. The most heavily PM2.5 polluted area is exactly from the central Asia desert region to eastern part of China, passing northern part of TP. In summary, rapid climate change and accelerating human activity, combined with special progresses on the TP, has led to a large uncertainty in resource, environmental and ecological change in this region. Therefore, it is necessary to study the patterns and driving mechanisms in the changes of resource and environment in the TP, to project future trends of changes, and to provide scientific evidences to decision-making regarding the sustainable development of the Silk Road Economic Belt, where human activities are intensity.
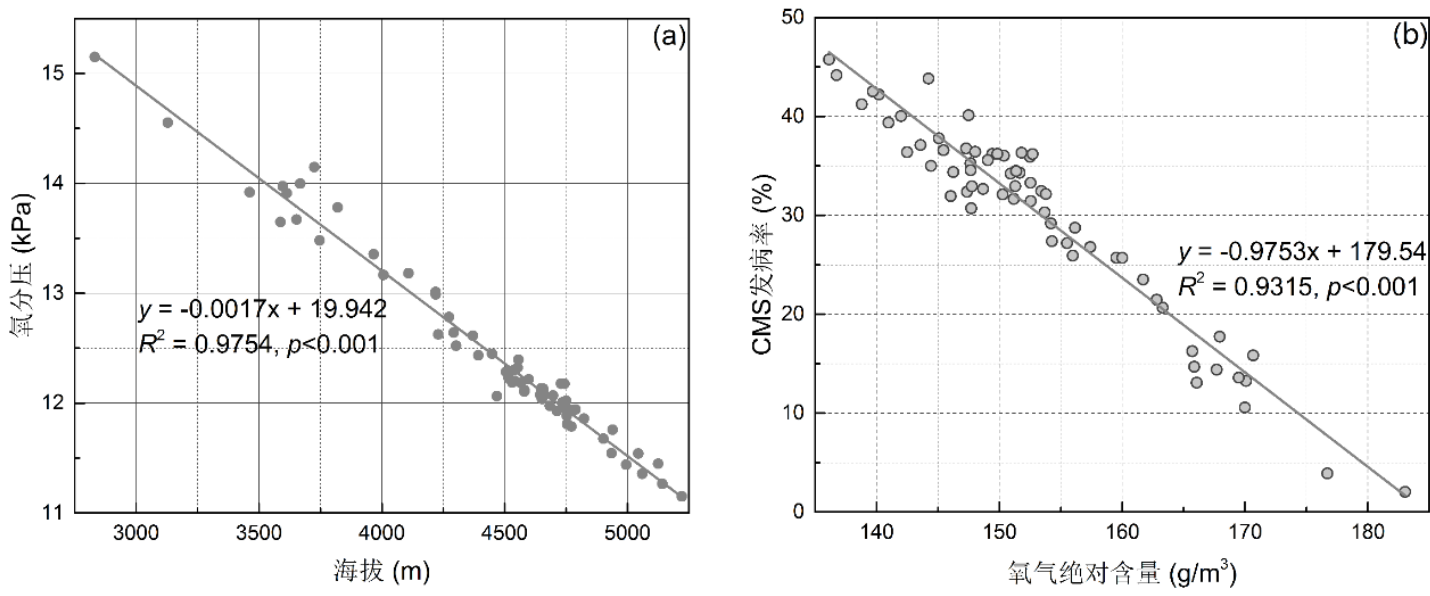

Figure 3. The relationships between altitude and oxygen partial pressure (a), between Absolute oxygen concentration and chronic mountain sickness incidence (Li et al. 2012, Cha et al. 2016, Shi et al. 2018)

The term of "The Tree Maxima" from President Xi (2018) has implied the bright prospect of ecological industry cluster. It is the common responsibility of the world to mitigate climate change, as well as to protect the Asian water tower. The most valuable is in ecology, in the dynamical, thermal and carbon sink function to global climate change, and in its water resources and ecosystem service. The biggest responsibility is in ecology, in protecting renewable natural resources, restoring ecosystem functions, and building eco-environment on the TP. It is the responsibility of the TP, of China, and of the world. The biggest potential lies in ecology, in ecological industry, serving as the safeguard of long-term development of the TP, and the sustainability of the Chinese nation and the world. Its potential is big ecological industry. " The three maxima" are interdependent, mutually reinforcing and organically unified, providing strategic countermeasures in the protecting the Asia water tower and points out the prospect for the development of ecological industry cluster. 
Shi et al., New understanding of climate change on the Qinghai-Tibetan Plateau and its adapting countermeasures

\subsection{Suggestions for climate change adaptation in the TP}

The rapid population growth in the TP, particularly the boom in the number of tourists (Figure 4.), calls for the development of green ecology, particularly the ecological industry cluster.

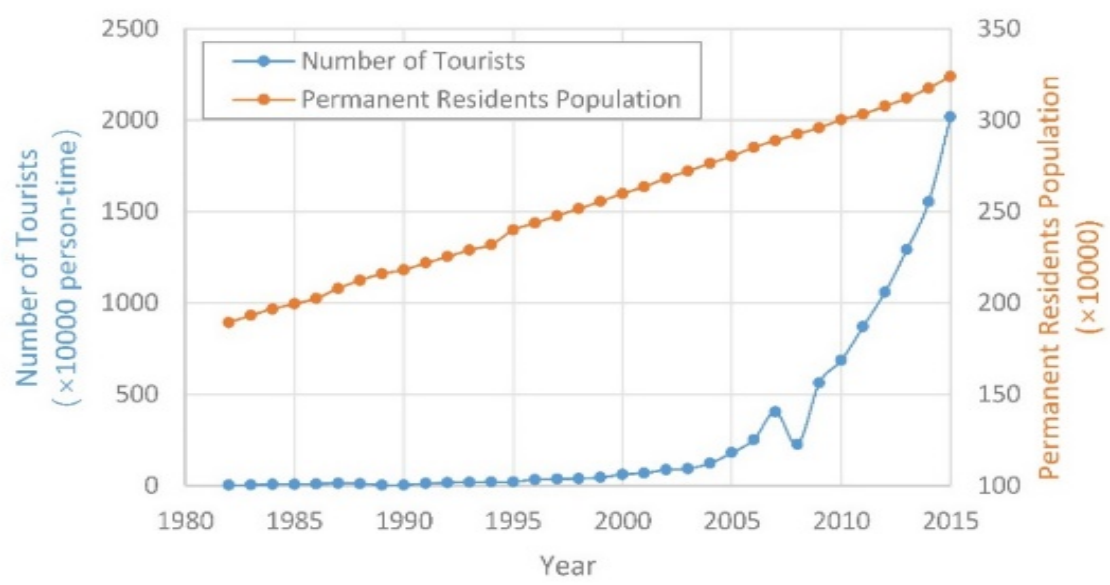

Figure 4. Changes in permanent residents of population and number of tourists in the TP (Tibet Autonomous Region Statistical Bureau, 2016)

First, flourish ecological industry, including the carbon-trade industry supported by "natural and microorganic technology", plateau animal husbandry integrating "natural grazing - facility farming", TP Chinese and Tibetan Medicine industry supported by coupled "natural growth - human planting" in extreme environment (strong sun-light, low oxygen concentration, alpine, arid, and saline), plateau sight-see industry using attracting landscapes of snow land, desert, high plains, and flat lakes. It is to protect, construct, and utilize well the ecology in the TP. The location of Qinghai-Tibet determines their extremely important and precious ecological value, and their greatest responsibility in protecting and building the TP ecological environment. Ecological protection is for the people, ecological construction depends on the people, and ecological utilization serves the people. Comprehensive development requires sustainable economic and social development. To balance the relationship among eco-environmental protection and construction and socio-economic development on the TP is the best choice in keeping with The Times. Flourishing ecological industry on the TP is an important manifestation of its ecological value, an important guarantee for the full implementation of the maximum responsibility, and a major project that brings out the maximum potential.

Second, build a strategic demonstration region of ecological conservation prioritized high-quality development and high-quality living. In order to implement the strategy of strategic demonstration region in Qinghai province, it requires to carefully study the impact of water resources on Golmud circular economic zone and the entire province. The strategic demonstration region is to achieve multiple wining in production, ecology, and life. Relying on the high ecological value of Qinghai province, deeply tap its ecological potential and give full play to its benefits, promote the harmonious coexistence of man and nature, and realize the "ecologicalized industrial development, industrialized ecological construction, and socialized life improvement".

Third, construct "high carbon absorption" experimental region. The impact of global climate change on the TP is mainly in its climate warming, as well as impact on glaciers, snow lines, permafrost and ecosystems. It is equally important to emphasize "low carbon emission" development and innovate "high carbon absorption" development system, to achieve a win-win situation of "emission reduction and sink increase". The role as a "source" of global warming of the TP urges us to deeply understand the significance of "low-carbon" development, including "low-carbon" technologies in production and life, and vigorously develop new energy industry. At the same time, the role as a "sink" of global warming of the TP reminds us to develop the "highcarbon absorption" technology in ecological construction to support carbon trade industry, and discuss the possibility of developing the technical-economic system of modern facility organisms industry (including microorganisms, plants and animals) of "high light efficiency, low water intensity, and high production", taking full advantages of abundant solar radiation and sufficient light in the TP. 
Shi et al., New understanding of climate change on the Qinghai-Tibetan Plateau and its adapting countermeasures

\section{REFERENCES}

Zhang YL, Li BY, Zheng D. (2002) A discussion on the boundary and area of the Tibetan Plateau in China. Geographical Research, 21(1), 1-9.

Yao T. (2018). The initial report of the second Qinghai-Tibet Plateau comprehensive scientific survey. Lasa, Tibet, China

Anyu Zhang, et al. (2018) Spatiotemporal changes of hazard intensity-adjusted population exposure to multiple hazards in Tibet during 1982-2015. International Journal of Disaster Risk Science, 9(4) 541-544.

Li, X., et al. (2012) Ecological study of community-level factors associated with chronic mountain sickness in the young male Chinese immigrant population in Tibet. Journal of epidemiology, 22(2), 136-143.

Zha RB, Sun GN, Dong ZB, YU ZK. (2016). Assessment of Atmospheric Oxygen Practical Pressure and Plateau Reaction of Tourists in the Qinghai-Tibet Plateau. Ecology and Environmental Sciences, 25(1), 92-98.

Tibet Autonomous Region Statistical Bureau. (2016). Tibet Statistical Yearbook. Beijing: China Statistical Press.

Xi, Jinping (2018). The three Maxima. People.cn, August 24th, , Xining, Qinghai, China

Shi PJ, Chen YQ, Zhang AY, et al. (2018). Factors contribution to oxygen concentration in Qinghai-Tibetan Plateau (in Chinese). China Science Bulletin, 63. 